\title{
The public health ethics framework and implications for COVID-19
}

\author{
AC Lundgren, ${ }^{1,2}$ iD HR Etheredge ${ }^{2,3}$ ic \\ ${ }^{1}$ Department of Anaesthesia, Steve Biko Centre for Bioethics, University of the Witwatersrand, South Africa \\ ${ }^{2}$ Wits Donald Gordon Medical Centre, South Africa \\ ${ }^{3}$ Department of Internal Medicine, University of the Witwatersrand, South Africa \\ Corresponding author, email: chris.lundgren@wits.ac.za
}

Keywords: bioethics, public health ethics, transparency, collective, individual

The current COVID-19 pandemic may require a shift in our ethical thinking - away from the widely endorsed framework of patientcentred care towards "public health ethics". At its core, public health ethics works towards the welfare of a majority in society, and as such, it is not usually applied to individual patients, but rather to a collective (for instance, society as a whole). This may call on us to redirect our efforts away from tirelessly promoting the autonomy of individual patients, towards the welfare of patients as a collective. During COVID-19, this confers a duty not only to existing patients under our care, but also to patients who may present with COVID-19.

It is essential to remember that public health ethics is a framework, and its principles are not over-riding. ${ }^{1}$ Public health ethics does not over-rule individual clinical decisions that we make for our current patients, however it may change decisions made if a current patient contracts COVID-19. We also need to remember that COVID-19 in South Africa is evolving, and if the situation changes, so too will our approach to it.

At its core, public health ethics requires the rationing of scarce healthcare resources in a manner that maximises population health. As an ethics framework, public health ethics sits firmly within the utilitarian camp.

Whilst healthcare rationing can be very uncomfortable for us, we need to acknowledge that it takes place worldwide on a daily basis. Although many of us may not be familiar with the direct implications of rationing, these do manifest in the South African private sector - especially when medical schemes refuse to fund particular treatments for patients. Rationing may be called for in our response to COVID-19 and it is likely to follow a "public health ethics" approach, which prioritises the welfare of those with good prognoses over those with very poor prognoses. Although rationing does not sit comfortably with many of us, it may be something we are going to have to confront in the coming weeks and months.

The key to ethical rationing within a public health framework is transparency. ${ }^{2,3}$ All patients must be managed according to an established clinical pathway for treatment and triage, which has been endorsed by the clinical team. This pathway needs to be flexible enough to accommodate individual clinical decisions for established or "known" patients, as well as robust enough to facilitate health maximisation for the collective. Having such a pathway in place empowers clinicians to make decisions and removes any perception that certain decisions have been made on a "ad-hoc" basis. It also empowers patients to understand their position in the health system and take necessary measures. (For instance, those over the age of 65, aware that a public health policy might not prioritise their ventilation in ICU, are thus in a position to practice rigorous self-isolation in order to avoid contracting COVID-19).

We have put together a table - illustrating the difference between 'modern' bioethics (that we are most familiar with and practice daily) and public health ethics. ${ }^{4}$ (See table on the next page.)

\section{Conflict of interest}

The authors declare no conflict of interest.

\section{Funding source}

None.

\section{ORCID}

AC Lundgren (iD https://orcid.org/0000-0001-9160-1562

HR Etheredge (iD https://orcid.org/0000-0002-2581-5754

\section{References}

1. Rosenbaum L. Facing covid-19 in Italy-ethics, logistics, and therapeutics on the epidemic's front line. N Engl J Med. 2020;382:1873-5. https://doi.org/10.1056/ NEJMp2005492.

2. O'Malley P, Rainford J, Thompson A. Transparency during public health emergencies: from rhetoric to reality. Bulletin of the World Health Organization. 2009;87:614-8. https://doi.org/10.2471/BLT.08.056689.

3. Alwan NA, Bhopal R, Burgess RA, et al. Evidence informing the UK's COVID-19 public health response must be transparent. Lancet. 2020;395:1036-7. https:// doi.org/10.1016/S0140-6736(20)30667-X.

4. Mahomed, S. Ethics and public health: A South African perspective. In: Nortjé N, De Jongh J, Hoffmann WA, editors. African perspectives on ethics for healthcare professionals. Springer; 2018. 


Public health ethics
Health maximisation - in a public health ethics context, health maximisation refers
to that of the collective community or society. This principle underpins the spirit of
public health ethics.

Efficiency - due to the scarcity of some healthcare resources, it is essential that those available are used efficiently. In public health ethics terms, efficiency requires consulting the available evidence base, and utilising scarce health resources to the benefit of a collective in order to "maximise health".

Non-maleficence ("Do not harm") - in a public health crisis may involve making trade-offs that directly harm a patient (or a group of patients) at the present, but with the intention of preventing harm to several patients who may present in the future. (This speaks to triage - triaging COVID-19 patients with very poor prognoses to palliative care and allocating scarce resources towards those who have better prognoses).

Beneficence (making an active contribution to the welfare of others) - in a public health ethics context, this principle again speaks to the long game. It involves viewing society as a collective whole who must benefit from a clinician's actions. As with non-maleficence, this can involve decision-making that disadvantages certain categories of patient in the short-term. In the context of public health ethics, this can be understood as "social beneficence" (i.e. making an active contribution to the welfare of the community as a whole).

Autonomy (the individual right to self-determination) - in public health ethics individual autonomy is often superseded by the needs of the collective. (In the current pandemic, for instance, an individual with major comorbidities and of very advanced age may express a wish for ventilation, and this may be refused based on principles of health maximisation and efficiency for the wider community). Legislation can be used to curb autonomy in public health responses. The onus for convincing the public that these measures are necessary rests with the relevant legislator in this case.

Justice (that people are treated equally) - in public health ethics, justice principles may be used to categorise persons into common groups who should be treated in a like manner.

Here again, the health of the collective is prioritised.

\section{Modern bioethics}

Health maximisation - in modern bioethics is often interpreted as directing health-maximising interventions to an individual patient in the micro-context of a consultation. It does not consider the health of a wider collective as a priority.

Efficiency - in modern bioethics efficiency is often driven by a cost-benefit analysis as applicable to a single patient. It does not necessarily consider the health maximisation of a wider collective.

Non-maleficence ("Do no harm") - usually directs clinician duties towards patients. Within the wider context of the patient's life and the Hippocratic Oath, this principle is self-explanatory.

Beneficence (making an active contribution to the welfare of others) - read in conjunction with non-maleficence, directs clinicians towards acting in a manner to further the welfare of an individual patient. Within the framework of patient centred care, this may involve directing maximum resources and effort towards an individual, known patient. It does not deal with hypothetical"future patients"as publichealth ethics does.

Autonomy (the individual right to self-determination) in general considered a grounding principle of modern bioethics. It is also the foundation of patient-centred care. In a micro-context, it entails direct involvement of a patient in decision-making, within the context of their individual health needs and considering their preferences and lifestyle.

Justice (that people are treated equally) - in modern bioethics this usually refers to the quality of healthcare services available, and the extent to which they are accessible. The South African health system is often accused of being "unjust" duetomajordiscrepanciesbetween the two health sectors, and sometimes within the sectors themselves. 